\title{
Regulation of PCP by the Fat signaling pathway
}

\author{
Maja Matis and Jeffrey D. Axelrod ${ }^{1}$ \\ Department of Pathology, Stanford University School of Medicine, Stanford, California 94305, USA
}

Planar cell polarity (PCP) in epithelia, orthogonal to the apical-basal axis, is essential for numerous developmental events and physiological functions. Drosophila model systems have been at the forefront of studies revealing insights into mechanisms regulating PCP and have revealed distinct signaling modules. One of these, involving the atypical cadherins Fat and Dachsous and the ectokinase Four-jointed, appears to link the direction of cell polarization to the tissue axes. We discuss models for the function of this signaling module as well as several unanswered questions that may guide future investigations.

The polarity of epithelial cells is reflected in the asymmetric localization of membrane domains, organelles, and external structures that form along the apical-basal axis and, in many tissues, also along a planar axis orthogonal to the apical-basal axis (Fig. 1). Coordinating the polarity of individual cells in a tissue to generate precisely organized tissue geometry is an essential feature of morphogenesis necessary for proper function. Polarization along the planar axis, referred to as planar cell polarity (PCP), is controlled by signaling mechanisms that orient asymmetric cellular structures and cell divisions and direct cell migration and oriented neighbor exchanges.

Mechanistically revealing studies of PCP have relied heavily on genetically tractable insect model systems. The most intensively studied of these is the Drosophila wing, which displays planar-polarized alignment of its $\sim 30,000$ cells, each producing a single trichome (or "hair") on the distal site of the cell (Fig. 1). It is important to note, however, that this is a manifestation of just one of several distinct and apparently independent mechanisms identified in flies that can produce planar polarization. The signaling system regulating PCP in the wing, together with the genetically closely related signals controlling polarity in the, eye, abdomen, and embryonic ventral epidermis (and undoubtedly other tissues), is commonly referred to as the PCP signaling system.

Planar polarization is likely present in most or all animals and contributes to a variety of developmental processes. A substantial body of evidence has shown that

[Keywords: Fat; intercellular signaling; planar cell polarity]

${ }^{1}$ Corresponding author

E-mail jaxelrod@stanford.edu

Article is online at http://www.genesdev.org/cgi/doi/10.1101/gad.228098.113.
PCP signaling components and the mechanisms in which they participate are evolutionarily conserved across the phylogenetic tree. As such, PCP has important functions in a broad array of developmental and physiological contexts, and defects in PCP signaling have been associated with many developmental anomalies and diseases. In vertebrates, PCP signaling operates in many contexts, and examples include convergent extension during anteroposterior $(\mathrm{A}-\mathrm{P})$ axis elongation, positioning of motile and sensory cilia, and polarization of skin and hair follicles (for review, see Wallingford 2012). Defects in PCP signaling have been associated with many developmental anomalies and diseases, including open neural tube defects (for review, see Simons and Mlodzik 2008; Copp and Greene 2010), polycystic kidneys (for review, see Simons and Walz 2006; Wallingford 2006; Wang and Nathans 2007; Simons and Mlodzik 2008), conotruncal heart defects (Garriock et al. 2005; Phillips et al. 2005, 2007; Henderson et al. 2006), deafness (Curtin et al. 2003; Montcouquiol et al. 2003, 2006; Lu et al. 2004; Davies et al. 2005; Wang et al. 2005, 2006a,b; Deans et al. 2007; Qian et al. 2007; Jones et al. 2008), and situs inversus (for review, see Santos and Reiter 2010). PCP is also believed to underlie the directed migration of malignant cells during invasion and metastasis (Weeraratna et al. 2002; Lee et al. 2004; Katoh 2005; Coyle et al. 2008; Kuriyama and Mayor 2008) and wound healing (Lee and Adler 2004; Caddy et al. 2010). These examples illustrate the importance of PCP in higher organisms. Not surprisingly, however, mechanistic studies in higher organisms lag substantially behind those from Drosophila, and this is particularly true for the Fat/Dachsous/Four-jointed (Ft/Ds/Fj) module that is the focus of this review. We therefore primarily describe work in Drosophila and briefly return to vertebrate studies at the conclusion.

Despite substantial gains in the past two decades, a firm understanding of the mechanisms that establish and maintain planar polarity remains elusive. It is well accepted that an underlying principle of PCP signaling is local communication between neighboring cells. This intercellular

(C) 2013 Matis and Axelrod This article is distributed exclusively by Cold Spring Harbor Laboratory Press for the first six months after the full-issue publication date (see http://genesdev.cshlp.org/site/misc/terms.xhtml). After six months, it is available under a Creative Commons License (AttributionNonCommercial 3.0 Unported), as described at http://creativecommons. org/licenses/by-nc/3.0/. 

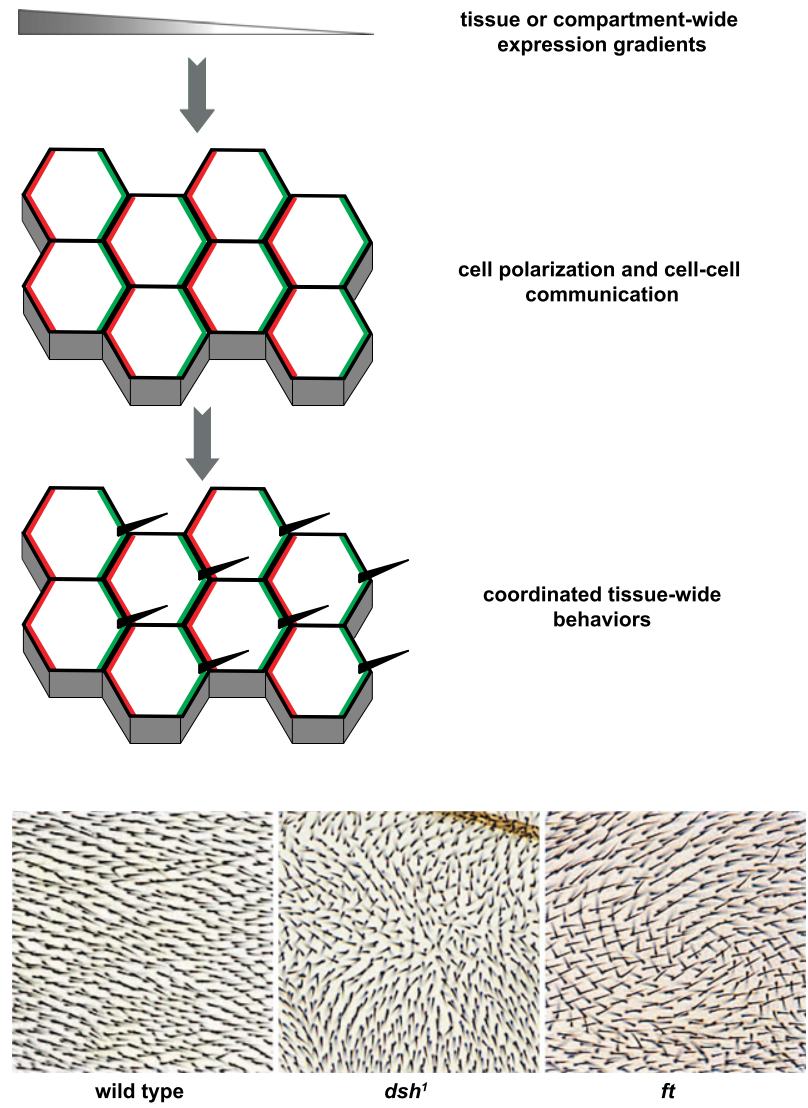

Figure 1. PCP in the Drosophila wing epithelium. Global directional cues, encoded by expression gradients or diffusion of secreted factors, provide directional information. The core module coordinates and amplifies polarity by intercellular communication and feedback mechanisms, localizing distinct protein complexes to opposite sides of the cell. Cells respond with appropriate tissue-specific behaviors. In the wing (and much of the adult cuticle), each cell produces a prehair from the distal side of the cell that points distally. Examples of wings showing polarity in wild type, a core mutant $\left(d s h^{1}\right)$, and a Ft/Ds/Fj module mutant $(f t)$.

signaling distinguishes PCP signaling from single-cell polarization mechanisms (e.g., chemotaxis) that are cellautonomous (for review, see Swaney et al. 2010). Consequently, the local alignment of individual cells is controlled by the emergent behavior of cellular ensembles. Here, we review our current understanding and major outstanding questions about the roles of the cadherins Fat and Dachsous in the PCP signaling process.

\section{PCP in flies}

In the wing-and similarly in most of the adult cuticle, including the abdomen-each cell produces a single trichome or "hair" on its apical surface. Hairs point distally (or posteriorly), forming a parallel array (Fig. 1). The location of prehair initiation determines its direction, as hairs are always seen to point away from the center of the cell; thus, prehair initiation on the distal side of the cell produces wild-type polarity. Therefore, by providing information to distinguish a specific side of the cell, PCP signaling determines the direction in which hairs point. The Drosophila eye is composed of $\sim 800$ ommatidia, each containing eight photoreceptor cells and other accessory cells. The eight photoreceptors in each ommatidium are arranged in either of two chiral forms along the dorso-ventral axis (Fig. 2). This chirality follows from the asymmetric fate specification of the R3 and R4 photoreceptor precursor pair. In wild type, R3 is specified closer to the equator, producing the normal pattern of dorsal and ventral chirality in either half of the eye. The R3 and R4 precursors are equipotent until PCP signaling specifies the direction of asymmetry (Zheng et al. 1995). Notch signaling between the precursors then directs the divergent cell fates, from which the opposite chiral morphologies follow (Cooper and Bray 1999; Fanto and Mlodzik 1999). Other tissues receive polarity information from the PCP pathway but have been less extensively studied and are not discussed further here.

\section{The PCP pathway}

Genetic and molecular analyses in the Drosophila wing, abdomen, and eye have identified components of the PCP pathway, and conserved function for many of the vertebrate homologs in PCP signaling has been demonstrated. On the basis of phenotype, genetic interactions, cell biology, and biochemical studies, these components can be divided into distinct functional modules (Tree et al. 2002a). The Ft/Ds/Fj module, sometimes referred to as the global module, is proposed to link the direction of polarization to the tissue axes (Yang et al. 2002; Ma et al. 2003). Recent evidence suggests that multiple global modules may coexist and cooperate in this function. The core module functions locally to coordinate and amplify molecular asymmetry within and between cells. Core module proteins segregate within cells into two distinct spatially separated complexes (for review, see Strutt and Strutt 2009). Via both intercellular and intracellular interactions, these proteins communicate and coordinate polarity information between neighboring cells that therefore orient as a group. Notably, the core module has no apparent intrinsic mechanism for orienting its action to the tissue axes. Finally, a variety of tissue-specific effector modules respond to signals from the global and core modules to mediate morphological polarization.

While both the $\mathrm{Ft} / \mathrm{Ds} / \mathrm{Fj}$ and core modules clearly function upstream of the tissue-specific modules, the relationship between the $\mathrm{Ft} / \mathrm{Ds} / \mathrm{Fj}$ and core modules is controversial. It was initially proposed that the $\mathrm{Ft} / \mathrm{Ds} / \mathrm{Fj}$ module acts upstream of the core module, orienting core module function that then amplifies and coordinates cell polarization (Yang et al. 2002; Ma et al. 2003). This model has been challenged by observations interpreted to indicate that the $\mathrm{Ft} / \mathrm{Ds} / \mathrm{Fj}$ module signals directly to tissuespecific modules (a "bypass" pathway) and that the Ft/Ds/ Fj module does not signal to the core module (Casal et al. 2006). However, the proposed existence of a bypass pathway does not logically exclude a signal from the Ft/Ds/Fj module to the core module, and we believe that current 

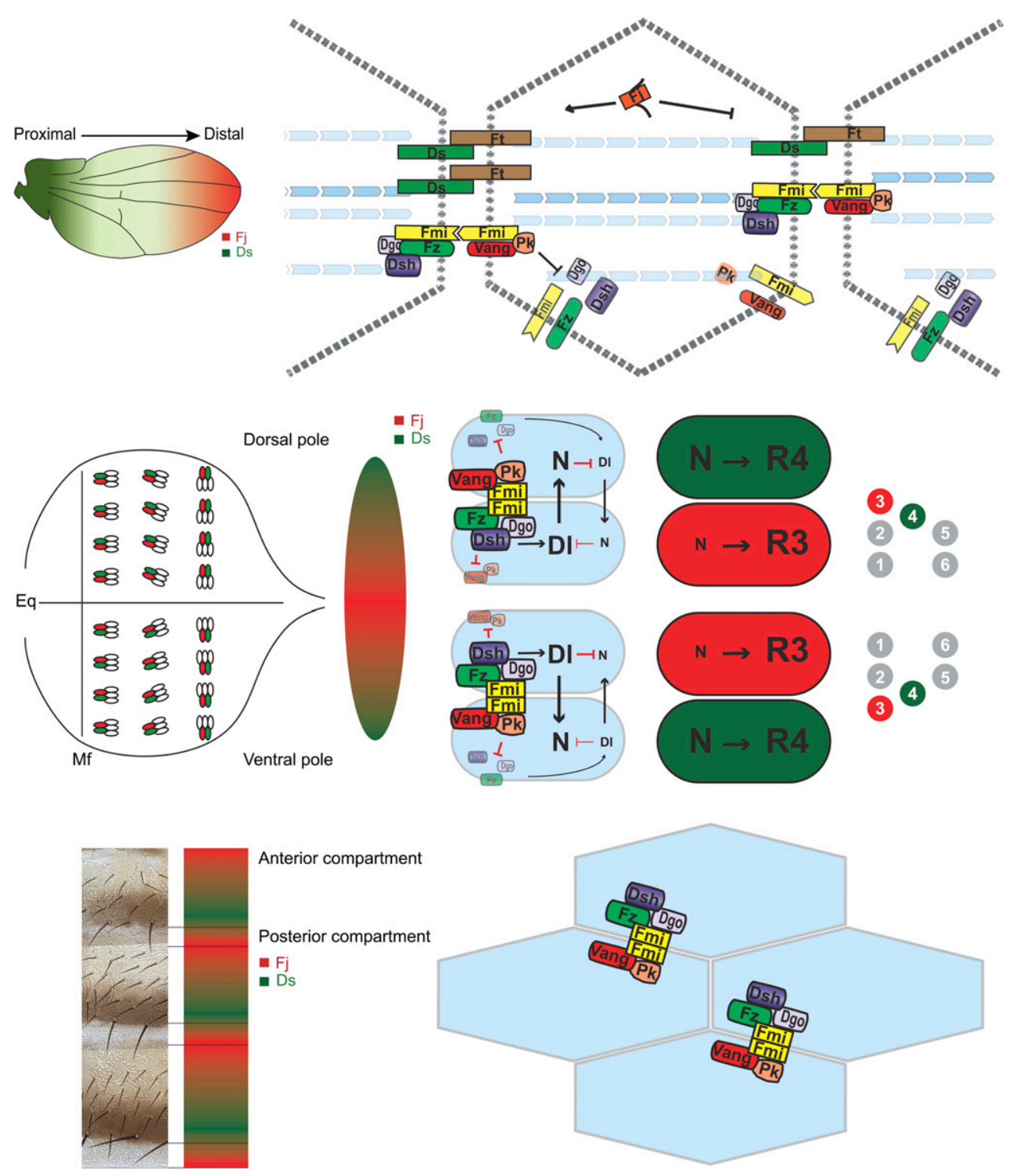

Figure 2. Schematics of polarization mechanisms in the wing, eye, and abdomen. Gradients of $\mathrm{Fj}$ and $\mathrm{Ds}$ in each tissue or compartment provide directional information. Core proteins (Fmi, Fz, Dsh, Dgo, Vang, and Pk) segregate to opposite sides of the cell. $\mathrm{Ft} / \mathrm{Ds} / \mathrm{Fi}$-dependent MTs may provide directional information to orient this segregation. In the eye, asymmetric core proteins bias Notch-Delta signaling between the R3 and R4 precursors, leading to dorsal and ventral polarity of ommatidia in the respective halves of the eye. In the abdomen, gradients of $\mathrm{Ds}$ and $\mathrm{Fj}$ are oppositely oriented in anterior and posterior compartments. Localization of core components is presumed based on hair polarity.

evidence allows for the possibility that output of the $\mathrm{Ft} /$ $\mathrm{Ds} / \mathrm{Fj}$ module is sensed by both the core and tissue-specific modules. This issue remains unresolved (Lawrence et al. 2007; Axelrod 2009) and is discussed only briefly here.

\section{Core module}

The core PCP machinery, defined in Drosophila and subsequently shown to be conserved in vertebrates, consists of six interacting proteins that, in a mutually interdependent way, segregate to distinct complexes on opposite sides of the cell. From an initial symmetric distribution, three of the six proteins, including the serpentine receptor
Frizzled (Fz) (Vinson and Adler 1987; Vinson et al. 1989), the multidomain cytoplasmic protein Dishevelled (Dsh) (Klingensmith et al. 1994; Theisen et al. 1994), and the ankyrin repeat protein Diego (Dgo) (Feiguin et al. 2001), become highly enriched at the distal (in the wing; equatorial in the eye; not yet reported in the abdomen) apicolateral domain of the cell cortex. The four-pass transmembrane protein Van Gogh (Vang) (Taylor et al. 1998; Wolff and Rubin 1998) and the prenylated LIM domain protein Prickle (Pk) (Gubb et al. 1999) segregate to the proximal (in the wing; polar in the eye) side. The sevenpass transmembrane cadherin Flamingo (Fmi) (Chae et al. 1999; Usui et al. 1999) localizes to both the proximal and 
distal (wing) sides (Fig. 2). Physical interaction data are consistent with a model in which the proximal (Fmi, Vang, and Pk) and distal (Fmi, Fz, Dsh, and Dgo) proteins exist in complexes, and the proximal and distal complexes interact between neighboring cells (Bastock et al. 2003; Jenny et al. 2003; Wong et al. 2003; Chen et al. 2008). It was proposed that these complexes are linked by Fmi homodimers that bridge across the intercellular space (Usui et al. 1999; Chen et al. 2008). The selectin Furrowed also appears to facilitate this intercellular interaction by stabilizing $\mathrm{Fz}$ in the membrane /Chin and Mlodzik 2013). Evidence for direct interaction between $\mathrm{Fz}$ and Vang has also been presented (Wu and Mlodzik 2008), although other evidence indicates that this interaction may not be essential (Chen et al. 2008). Consistently, studies using mosaic analyses showed that the proximal complex recruits the distal complex to the membrane of neighboring cells and vice versa, and, at the same time, each complex also blocks recruitment of the other complex to the same side through a mutual exclusion mechanism (Tree et al. 2002b; Amonlirdviman et al. 2005; Strutt and Strutt 2007). Together, these interactions constitute a bistable switch, tending toward an allor-none accumulation of proximal and distal complexes oriented in one direction. Several documented intracellular physical interactions may contribute to this activity (Tree et al. 2002b; Das et al. 2004; Jenny et al. 2005), but specific mechanisms are unknown.

In the fly wing, $\mathrm{Fz}$ accumulates on the distal side and Vang accumulates on the proximal side of the cell, where, by a poorly defined mechanism, they specify the location for prehair initiation. In the eye, Fz localizes to the R3 side of the R3/R4 precursor border and Vang localizes on the R4 side of the same border, directing preferential Delta expression in the prospective $\mathrm{R} 3$ and Notch expression and activation in the prospective R4 (Fig. 2; Cooper and Bray 1999; Fanto and Mlodzik 1999; Strutt et al. 2002).

\section{Global modules}

The core PCP module locally coordinates and amplifies polarity but requires information to correctly orient local polarity with respect to the tissue axes. It has long been presumed that such information would be encoded in the form of diffusion or expression gradients of one or more key signaling molecules along the tissue axes. The Ft/Ds/ $\mathrm{Fj}$ module meets these criteria, as both $\mathrm{Ds}$ and $\mathrm{Fj}$ are expressed in oppositely oriented gradients in each of the well-studied tissues and compartments (Clark et al. 1995; Brodsky and Steller 1996; Yang et al. 2002; Ma et al. 2003). The model holds that expression gradients of $\mathrm{Ds}$ and $\mathrm{Fj}$ provide directional information, which is converted into oriented subcellular asymmetries that are interpreted by downstream mechanisms. In brief, the atypical cadherins Ft and Ds form asymmetric heterodimers that may orient in either of two directions at any apical cell-cell boundary. The Golgi resident protein Four-jointed ( $\mathrm{Fj}$ ) (Villano and Katz 1995; Zeidler et al. 2000; Yang et al. 2002; Ma et al. 2003) phosphorylates extracellular domains of Ds and $\mathrm{Ft}$ and modulates their binding, enhancing the affinity of Ft for Ds and diminishing the affinity of Ds for Ft (Ishikawa et al. 2008; Brittle et al. 2010; Simon et al. 2010). Heterodimers with biased orientation then provide directional cues to downstream systems. Flies mutant (in either whole tissue or large clones) for these proteins and thus lacking the global directional cue display swirling hair polarity patterns (Fig. 1). The strong local polarity coordination and observed asymmetry of core PCP proteins indicate intact function of the core module but absence of global alignment.

A distinct global orienting cue could be provided by Wnt family proteins. These diffusible ligands are ideal candidates, as they bind to Fz family receptors (among others) and could produce a gradient of $\mathrm{Fz}$ activity. Indeed, Wnt5a, Wnt7a, and Wnt11 have been shown to control PCP in vertebrates (for review, see Vladar et al. 2009; Gao and Yang 2013), but little convincing data have emerged to show that they can provide directional information. Similarly, in Drosophila, it was shown that DWnt4 mutant eyes display PCP defects in a small region where DWnt4 is normally expressed (Lim et al. 2005). A more recent study suggests that Wingless $(\mathrm{Wg})$ and DWnt4 act redundantly to provide directional information close to the wing margin (Wu et al. 2013) where these Wnts are coexpressed and believed to diffuse to form a gradient (Couso et al. 1994; Lim et al. 2005; Chen et al. 2008). A model has been proposed in which Wg and DWnt4 directly orient the core PCP module by modulating local interaction between $\mathrm{Fz}$ and Vang in a graded manner (Wu et al. 2013). Thus, at least in the wing, Wnts likely provide a global cue to orient PCP. Additional arguments suggesting a multiplicity of global signals are described below.

\section{Diversity of planar polarity signaling pathways}

The PCP pathway described above controls many planar polarization events in Drosophila, but at least several tissues display planar polarization that is under the control of distinct regulatory mechanisms. The embryonic ectoderm undergoes tissue elongation and narrowing during germ band extension. Polarized junctional rearrangements direct this tissue reorganization and depend on planar polarity that is independent of the PCP signaling proteins described above (Zallen 2007; Bertet and Lecuit 2009; Vichas and Zallen 2011). Another planarpolarized cell behavior that does not rely on the PCP pathway is the elongation of the Drosophila egg chamber during oogenesis. Interestingly, this event requires Fat2, a Fat homolog, and the receptor tyrosine phosphatase Lar for the planar-polarized orientation of actin filaments in follicle cells (Gutzeit 1990; Viktorinova et al. 2009).

\section{The Ft/Ds/Fi module and interaction with the core PCP signaling pathway}

Introduction to Fat, Dachsous, and Four-jointed: PCP and Hippo growth pathway regulation

Fat (Mahoney et al. 1991) and Ds (Clark et al. 1995) were initially identified as tumor suppressors and only later 
shown to have functions in PCP regulation (for review, see Reddy and Irvine 2008; Staley and Irvine 2012). Their tumor suppressor function depends on regulation of the Hippo growth regulatory pathway, likely by regulating the level and localization of the Hippo pathway component Expanded (Bennett and Harvey 2006; Silva et al. 2006; Willecke et al. 2006) and the levels of Warts (Cho et al. 2006; Feng and Irvine 2007). The final Hippo pathway target is the transcriptional coactivator Yorkie (Yki). Activation of the pathway results in phosphorylation of Yki by Warts and its retention in the cytoplasm (Huang et al. 2005; Dong et al. 2007). In the absence of signal, translocation of Yki into the nucleus promotes cell proliferation and growth and inhibits apoptosis, resulting in massive overgrowth and larval lethality. Interestingly, regulation of both the PCP and Hippo pathways depends on expression gradients of Ds and Fj. The vector of these gradients provides directional information for PCP signaling (Yang et al. 2002; Ma et al. 2003; Simon 2004), while the slope regulates Hippo-dependent responses (Rogulja et al. 2008). Regulation of Hippo signaling by $\mathrm{Ft} / \mathrm{Ds} / \mathrm{Fj}$ has been thoughtfully reviewed elsewhere and is not discussed at length here (Reddy and Irvine 2008; Staley and Irvine 2012).

\section{Structure of Fat, Ds, and Fj}

Ft The Drosophila Fat protein is a member of the cadherin superfamily, a group of type I integral membrane proteins characterized by the presence in the extracellular domain of cadherin-type repeats composed of two $\beta$ sheets mediating $\mathrm{Ca}^{2+}$-dependent binding. Ft contains
34 tandem cadherin-type repeats, five epidermal growth factor (EGF)-like repeats, and two laminin G-like domains in its extracellular region followed by the transmembrane and intracellular domains (Fig. 3). Ft is predicted to encode a 5147-amino-acid protein with a calculated mass of $560 \mathrm{kDa}$ and is expressed at significant levels in a number of epithelia. Ft is constitutively cleaved at either of two sites (Fig. 3) located in the extracellular domain of the protein (Feng and Irvine 2009), but it is not yet known whether these modifications are associated with any function. $\mathrm{Ft}$ is phosphorylated by $\mathrm{Fj}$, a Golgi-localized ectokinase, on four cadherin domains $(3,5,11$, and 13) (Ishikawa et al. 2008), and this modification increases the binding affinity between Ft and Ds cadherin repeats (Simon et al. 2010).

The intracellular portion of $\mathrm{Ft}$ does not contain conserved domains. It is phosphorylated by Discs overgrown (Dco) in a Ds-dependent manner (Feng and Irvine 2009; Sopko et al. 2009). There is conflicting evidence as to whether this modification is required for regulation of Hippo signaling by Ft (Matakatsu and Blair 2012; Pan et al. 2013), but it appears to be dispensable for PCP regulation (Pan et al. 2013). The Ft intracellular domain also interacts with Lowfat (Lft; in lft mutants, Ft expression is reduced) (Mao et al. 2009) and Atrophin (also known as Grunge) (Fanto et al. 2003). Surprisingly, all known protein interaction domains in the Ft intracellular domain appear to be dispensable for Hippo and PCP pathway function (Matakatsu and Blair 2012; Pan et al. 2013; Zhao et al. 2013). For example, the Ft $\Delta \mathrm{ECD} \Delta 1-\mathrm{C}$ construct (Fig. 3) rescues ft mutant overgrowth (Hippo pathway) and PCP defects but lacks the binding regions identified for Lowfat, Grunge, and Dco (Matakatsu and

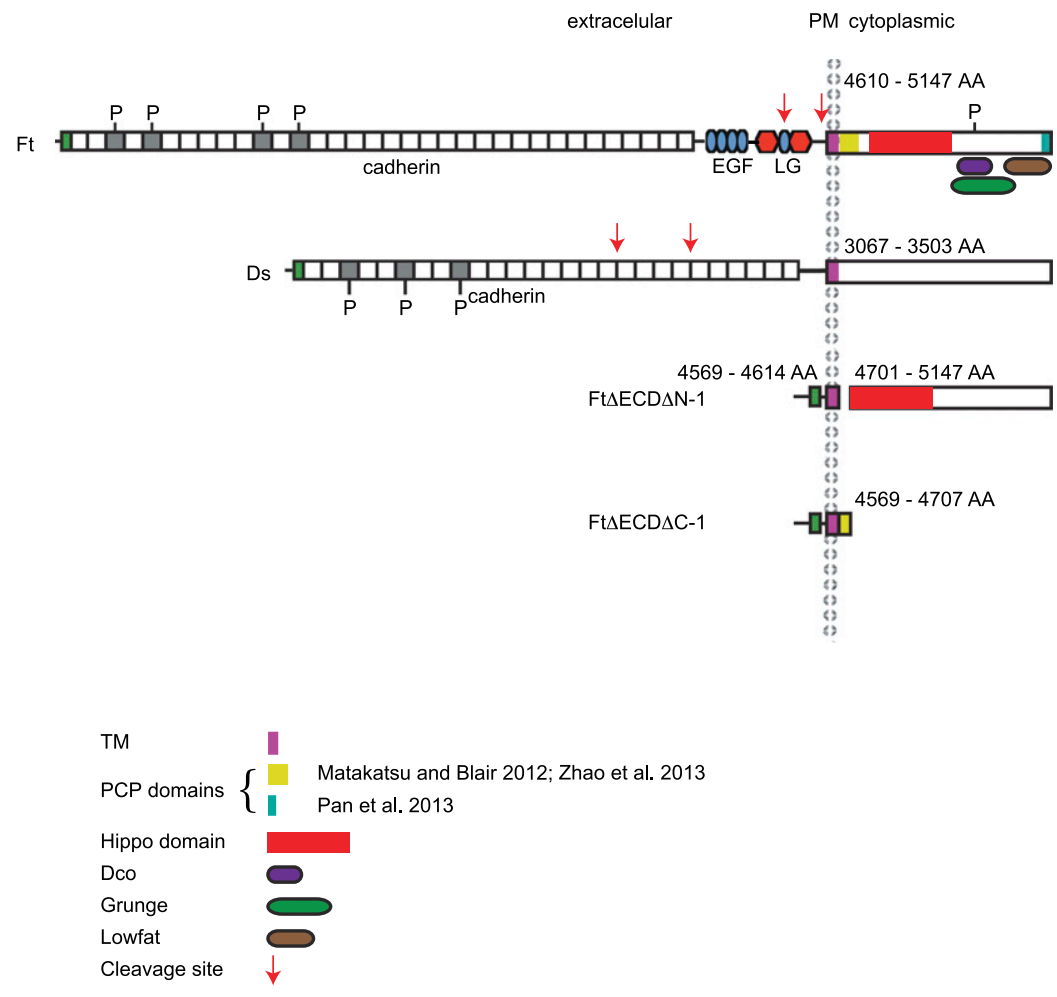

Figure 3. Cartoons of Fat, Dachsous, and truncated Fat derivatives. Conserved extracellular domains are indicated. Sites of phosphorylation by Fj are marked with " $\mathrm{P}$," and cleavage sites are marked with arrows. Known intracellular binding sites are shown, as are putative functional domains identified by various structure/function studies. Ft $\Delta \mathrm{ECD} \Delta \mathrm{N}-1$ and Ft $\Delta \mathrm{ECD} \Delta 1-\mathrm{C}$ were constructed by Matakatsu and Blair (2012). 
Blair 2012). However, these somewhat crude assays may well obscure functions for these domains.

Ds Like Ft, the Drosophila Ds protein is a type I transmembrane cadherin protein with 27 cadherin repeats followed by the transmembrane and intracellular domains. $D s$ is predicted to encode a 3503-amino-acid protein with a calculated mass of $380 \mathrm{kDa}$. Ds is expressed in the embryonic ectoderm, imaginal discs, and the brain (Clark et al. 1995). In contrast to $\mathrm{Ft}$, Ds is expressed in gradients that may contribute to its ability to provide directional information (and growth regulatory activity), as discussed below (Zeidler et al. 1999; Casal et al. 2002; Yang et al. 2002; Ma et al. 2003; Lawrence et al. 2004). Biochemical analyses of Ds revealed that the protein undergoes proteolytic processing at two alternative cleavage sites located in the extracellular domain (Fig. 3; Feng and Irvine 2009). The cleavage is Ft-dependent, as the balance is shifted toward one preferred site in $\mathrm{ft}$-null wing discs. Ds is phosphorylated by $\mathrm{Fj}$ on three cadherin domains (3, 6, and 9) (Ishikawa et al. 2008), and this modification decreases its affinity for Ft with demonstrated consequences for the polarity function of Ds (Brittle et al. 2010; Simon et al. 2010). The intracellular domain of Ds binds to Dachs (Bosveld et al. 2012). Dachs is important in Hippo pathway regulation and may also participate in regulating PCP.

Fj Fj encodes a type II transmembrane protein (Villano and Katz 1995; Zeidler et al. 2000) with kinase activity (Ishikawa et al. 2008). $\mathrm{Fj}$ is expressed in gradients along the proximal-distal (P-D) axis in imaginal discs (Zeidler et al. 1999; Casal et al. 2002; Yang et al. 2002; Ma et al. 2003; Lawrence et al. 2004) and is largely localized to the Golgi in vivo and in transfected cells (Strutt et al. 2004). Four-jointed phosphorylates the cadherin domains of $\mathrm{Ft}$ and Ds as they transit through the Golgi (Ishikawa et al. 2008). An acidic sequence motif (Asp-Asn-Glu) within Fj is essential for its kinase activity in vitro and its biological activity in vivo.

\section{Model of Ft/Ds/Fj function in PCP}

The discovery of functions for Ft/Ds/Fj in PCP offered an alternative to the prevailing view that diffusible factors would provide the gradient signal for a global directional cue in PCP signaling. The module is proposed to convert transcription gradients of $\mathrm{Fj}$ and $\mathrm{Ds}$ into subcellular asymmetries of Ds-Ft heterodimers that reside at adherens junctions (AJs) (Yang et al. 2002; Ma et al. 2003). The mechanism and evidence supporting it are described at length below. The essential feature of this mechanism is that it captures information about the direction of the tissue axes and provides subcellular asymmetric molecular cues that are available to orient PCP to the tissue axes.

Epistasis of Ft/Ds/Fj and core modules

Epistasis experiments in the eye (Yang et al. 2002; Simon 2004) indicate that $d s$ and $f j$ function through Ft to provide a polarity signal, and experiments in the eye and wing (Yang et al. 2002; Ma et al. 2003) suggest that the signal from Ft serves to orient the core PCP module. Within clones of $f t, d s$, or $f j$, the core module retains function, as evidenced in the wing by asymmetrically localized core PCP proteins and the local alignment of polarity. However, orientation of polarity is dissociated from the tissue axes, indicating a loss of global directional input. If, on the other hand, the Ft/Ds/Fj system did not orient core function, one would expect to observe normally oriented core PCP protein localization in clones despite misoriented hair polarity. This epistasis relationship is clearer in the eye, where clonal analysis demonstrates that Ft expression in either R3 or R4 influences ommatidial polarity only in the presence of $\mathrm{Fz}$ (Yang et al. 2002). Recent experiments provided additional evidence favoring this model for the eye but challenge the view in other Drosophila tissues (Simon 2004; Casal et al. 2006; Mao et al. 2006; Repiso et al. 2010; Donoughe and DiNardo 2011). Flattening the gradients of $\mathrm{Fj}$ and $\mathrm{Ds}$ disrupts polarity in the eye (Simon 2004), as the model would predict, but in the same flies, polarity in the wing is only disturbed in limited regions. Thus, in the wing, expression of these components is necessary, but the gradients of expression are less critical for function. A very limited requirement for core protein function in tissues that depend on $\mathrm{Ft} / \mathrm{Ds} / \mathrm{Fj}$ is also difficult to reconcile with a simple epistatic relationship (Repiso et al. 2010; Donoughe and DiNardo 2011). Nonetheless, it must be noted that the $\mathrm{Ft} / \mathrm{Ds} / \mathrm{Fj}$ and core modules cannot simply be considered redundant, as mutations in either system produce at least some polarity disruption that is not rescued by the other module.

\section{A bypass pathway?}

The results described above led to the proposal that output from the $\mathrm{Ft} / \mathrm{Ds} / \mathrm{Fj}$ module bypasses the core module and is used directly by tissue-specific modules. The essential experiment leading to this proposal is the observation that cells overexpressing Ft or an active form of Ds cause repolarization of adjacent cells even if they are mutant for $f z$ or $f m i$ (Casal et al. 2006; Lawrence et al. 2007). A similar result was observed in ventral embryonic epidermis (Donoughe and DiNardo 2011). How could these adjacent cells respond by altering their polarity if polarity depends on a core module downstream from Ft/ $\mathrm{Ds} / \mathrm{Fj}$ and the core module is disabled? This is essentially an epistasis experiment, and the interpretation depends entirely on the presumption that the putative "downstream" module is null for all function when mutant for $f z$ or fmi (Avery and Wasserman 1992). Evidence indicating that this condition is not satisfied weakens the conclusion and has been discussed at length elsewhere (Axelrod 2009). Furthermore, it is known that propagation of asymmetry occurs within the $\mathrm{Ft} / \mathrm{Ds} / \mathrm{Fj}$ module (much as it does in the core module), so that asymmetry of Ft-Ds at the overexpression boundary will produce asymmetry in nearby cells (described below), thereby delivering a signal to the nearby cells. Therefore, we 
believe that the existence of a bypass pathway is possible but has not yet been adequately tested, and the ultimate demonstration would require identifying its mechanism. Of course, the existence, or not, of a bypass pathway is independent of and has no bearing on whether the Ft/Ds/ Fj module signals to the core module. Finally, it is worth noting that many of the relevant experiments have been performed in only one tissue, leaving open the possibility of tissue-specific differences in pathway architecture. Although it is possible that interaction between $\mathrm{Ft} / \mathrm{Ds} / \mathrm{Fj}$ and the core module varies by tissue, we favor more conservative models unless proven otherwise.

\section{Multiplicity of global signals}

One explanation for the failure of flattened $\mathrm{Ds}$ and $\mathrm{Fj}$ gradients to produce polarity defects across the entire wing is redundancy of global signaling systems. The existence of multiple global cues (Lim et al. 2005; Sagner et al. 2012; Wu et al. 2013) could explain the limited polarity defects in tissues mutant for $\mathrm{ft}$ or $d s$ but having rescued Hippo signaling (Mao et al. 2006; Matakatsu and Blair 2006, 2012; Brittle et al. 2012). In these animals, hairs are misoriented only in part of the wing and abdomen. The most direct evidence to date for additional directional signals is the finding that Wnts secreted from the wing margin provide such a signal, at least in the wing (Wu et al. 2013), while other findings at least imply the possibility of multiple such signals (Sagner et al. 2012).

Another clue suggesting the existence of additional directional signals comes from the embryonic ventral epidermis, where columns of denticle-producing cells are polarized with contributions from both $\mathrm{Ft} / \mathrm{Ds} / \mathrm{Fj}$ and core modules (Price et al. 2006; Repiso et al. 2010; Donoughe and DiNardo 2011). Here, unexpected polarity reversals are observed in $d s f z$ double mutants that are not observed in either single mutant, suggesting that impairing both modules unmasks the activity of an additional signal working in opposite directions in parts of the tissue (Donoughe and DiNardo 2011). Future studies will reveal whether yet other systems also contribute to coordinating PCP with the tissue axes.

\section{Pathway architecture}

Although it remains controversial, we believe that the best interpretation of existing data is that the $\mathrm{Ft} / \mathrm{Ds} / \mathrm{Fj}$ module serves as a global module, acting upstream and providing directional information to the core PCP module, and that the existence of a bypass pathway remains an open question. However, it seems clear that the Ft/Ds/ $\mathrm{Fj}$ module is not the sole global cue, as was originally proposed. Global signals might act upstream of and orient the core module or act in parallel to the core module. The existence of multiple global cues acting upstream of the core module can, we believe, fully explain existing data regarding the wing without invoking bypass pathways. Similarly, in the eye, the best model is that the $\mathrm{Ft} / \mathrm{Ds} / \mathrm{Fj}$ module acts upstream and provides directional information to the core module. The relative paucity of data makes the situation in the abdomen more difficult to interpret. While others have proposed that here the $\mathrm{Ft} /$ Ds/Fj module acts in parallel with the core module, we believe that either a series, a parallel, or a combined architecture is possible. While it is of course conceivable that the $\mathrm{Ft} / \mathrm{Ds} / \mathrm{Fj}$ and core modules interact differently in different tissues, we suggest that working models should favor the likelihood of similarities rather than differences. To accurately describe the role of the $\mathrm{Ft} / \mathrm{Ds} / \mathrm{Fj}$ module in regulating PCP, a more detailed understanding of factors that influence how Ft, Ds, and Fj interact with each other as well as the cell biological and biochemical signals they provide as outputs is urgently needed.

\section{A rectification problem}

An interesting puzzle not yet adequately explained by any model is the inconsistent relationship between the direction of core module polarization (as indicated by hairs or asymmetric PCP protein segregation) and the direction of the Ds and $\mathrm{Fj}$ gradients. For example, in the wing, Fz segregates to the side of the cell closer to the high end of the Fj gradient (Zeidler et al. 2000; Strutt 2001), while in the eye, it segregates to the side of the cell closer to the low end of the Fi gradient (Zeidler et al. 1999; Strutt et al. 2002). In the fly abdomen, which is composed of repeating anterior and posterior segments, anterior and posterior have opposite relationships, with the anterior resembling the eye and the posterior resembling the wing (Casal et al. 2002). Regardless of whether the $\mathrm{Ft} / \mathrm{Ds} / \mathrm{Fj}$ module acts on the core module or in parallel, a system for rectifying what would appear to be oppositely oriented inputs in some of the tissues is needed.

\section{Mechanism of Fat/PCP polarity regulation}

\section{The heterodimer model}

The $\mathrm{Ft} / \mathrm{Ds} / \mathrm{Fj}$ module is proposed to function by converting transcription gradients of $\mathrm{Fj}$ and $\mathrm{Ds}$ into subcellular asymmetries of Ds-Ft heterodimers (Yang et al. 2002; Ma et al. 2003). Ft and Ds localize to AJs, where they form heterodimers that can orient in either of two directions. $\mathrm{Fj}$ was proposed to make $\mathrm{Ft}$ a stronger ligand and Ds a weaker ligand for the other. As $\mathrm{Fj}$ and Ds are expressed in opposing gradients across tissues, the gradients redundantly promote the accumulation of an excess of FtDs heterodimers in one orientation relative to the other (Fig. 2). The net result is a conversion of directional information contained in transcriptional gradients of $\mathrm{Fj}$ and Ds into subcellular gradients of Ds-Ft heterodimers. These subcellular gradients can then provide information to regulate orientation of polarization according to the direction of the gradients by mechanisms that are not yet identified. Opposing Ds and Fj gradients are observed in all polarized Drosophila tissues studied to date and are established early in development, when the tissues are small (Clark et al. 1995; Zeidler et al. 1999, 2000; Yang et al. 2002). In the wing disc, proximodistal patterning occurs in response to $\mathrm{Wg}$ from the dorso-ventral compartment boundary and Dpp from the A-P compartment boundary. These morphogens directly or indirectly shape 
the gradients of Ds and Fj expression in the wing /Cho and Irvine 2004; Rogulja et al. 2008; Zecca and Struhl 2010), with high expression of Ds in the proximal part and $\mathrm{Fj}$ in the distal part of the wing. In the eye, the Ds and $\mathrm{Fj}$ expression gradients are established by a combination of Wg, JAK/STAT, and Notch signaling along the dorsoventral axis (Zeidler et al. 1999; Yang et al. 2002), and in the abdomen, these gradients are established by $\mathrm{Wg}$ and Hh along the A-P axis (Struhl et al. 1997; Casal et al. 2002; Lawrence et al. 2002). As the tissues grow, these gradients are predicted to become very shallow but may be maintained by feedback regulation (Yang et al. 2002; Rogulja et al. 2008).

The Ft-Ds heterodimer model is central to current views of $\mathrm{Ft} / \mathrm{Ds} / \mathrm{Fj}$ module function and allows for biased orientation that depends on the directions of $f j$ and $d s$ transcription gradients. The observation that $\mathrm{Ft}$ and Ds form heterodimers was originally made in the wing, where Ft in $d s$ clones is recruited to the side of the cell in contact with wild-type cells expressing Ds and vice versa (Ma et al. 2003; Matakatsu and Blair 2004), and was subsequently confirmed in cultured cells, where $\mathrm{Ft}$ and Ds mediate heterophilic interaction between cells (Matakatsu and Blair 2004; Simon et al. 2010). By measuring affinities in cell culture assays, it was shown that the interaction between $\mathrm{Ft}$ and $\mathrm{Ds}$ is regulated by Fj kinase, which phosphorylates cadherin domains of Ds and Ft (Ishikawa et al. 2008), presumably during passage through the Golgi, increasing the affinity of $\mathrm{Ft}$ for Ds and weakening the affinity of Ds for Ft (Brittle et al. 2010; Simon et al. 2010). In vivo evidence for this model of $\mathrm{Fj}$ function comes from the observations that overexpressing $\mathrm{Fj}$ in $d s$ clones, thereby phosphorylating $\mathrm{Ft}$, enhances recruitment of Ds to the adjacent side of neighboring wild-type cells (Simon et al. 2010). Conversely, overexpression of $\mathrm{Fj}$ in $\mathrm{ft}$ clones, phosphorylating Ds, decreases recruitment of Ft in adjacent wild-type cells (Simon et al. 2010).

Asymmetric orientation of $\mathrm{Ft}-\mathrm{Ds}$ heterodimers is predicted to result from oppositely oriented expression gradients of Ds and Fj through the interactions described above and may, in principle, provide a vector that could orient PCP. Importantly, the inferred asymmetric subcellular localization of $\mathrm{Ft}-\mathrm{Ds}$ heterodimers was only recently demonstrated to indeed exist and is observed where the gradients of $\mathrm{Ds}$ and $\mathrm{Fj}$ appear to be steepest (Ambegaonkar et al. 2012; Bosveld et al. 2012; Brittle et al. 2012). In the Drosophila notum where this polarization was first reported (Bosveld et al. 2012), enrichment of Ds along cell borders orthogonal to the $d s$ and $f j$ gradients contributes to planar polarization of tissue and controls tissue morphogenesis. It is proposed that elevated Ds accumulation binds and locally recruits the myosin Dachs, generating tension and consequently contraction that results in junctional rearrangements. Asymmetric subcellular accumulation of Ft, Ds, or Dachs has now been observed in Drosophila wing (Ambegaonkar et al. 2012; Brittle et al. 2012) and eye (Brittle et al. 2012) discs in patterns consistent with control by the $d s$ and $f j$ expression gradients, lending additional evidence to the hypothesis that expression gradients of $f j$ and $d s$ lead to polarization of $\mathrm{Ft}$ and Ds within cells. The polarization is weaker than observed for core PCP protein polarization, consistent with the early proposal that this system provides a weak directional signal that is amplified by the core module (Ma et al. 2003).

It seems unlikely that the mechanism described above could produce a substantial or even detectable difference in Ds and Ft localization across individual cells without an amplification mechanism. The existence of such an amplification mechanism would, in addition to strengthening polarization of these proteins, also explain the observed propagation of polarization into neighboring cells when Ft or Ds expression is manipulated in clones (Ambegaonkar et al. 2012; Brittle et al. 2012). Accumulation of Ft in one cell would recruit Ds within neighboring cells or vice versa, and amplification would facilitate the corresponding enrichment and depletion on the opposite side of the neighboring cell. A propagation mechanism for the $\mathrm{Ft} / \mathrm{Ds} / \mathrm{Fj}$ module was predicted computationally (Ma et al. 2008), and propagation of asymmetry is in fact seen in wing discs around clones overexpressing Ds (or activated forms thereof), where propagation of asymmetric Ds and D localization is observed perpendicular to the clone boundary up to several cell diameters from the clone (Ambegaonkar et al. 2012; Brittle et al. 2012). The observed nonautonomy of the $\mathrm{Ft} / \mathrm{Ds} / \mathrm{Fj}$ module is reminiscent of the nonautonomy produced by the core PCP module, albeit weaker. Propagation of core PCP module polarization spans as many as 10 cell diameters, while propagation of Ds polarization around Ds-overexpressing clones is typically seen to reach only two to four cells away from the clone. Dachs, a downstream component of Fat signaling (perhaps in PCP as well as Hippo signaling), is also polarized in wing and eye discs (Mao et al. 2006; Ambegaonkar et al. 2012; Brittle et al. 2012), and its asymmetry is propagated in the same manner as asymmetry of Ds. Dachs asymmetry is seen up to four to five cells away from Ds-overexpressing clone boundaries (Ambegaonkar et al. 2012; Brittle et al. 2012). The stronger polarization of Dachs compared with Ft and Ds might indicate an amplification mechanism downstream from Ft and Ds or may simply reflect the possibility that detection of Dachs is more robust than that of Ds.

No mechanism that amplifies initial differences in oriented Ft-Ds heterodimers has been identified, but a characteristic of such amplification mechanisms is mutual antagonism between oppositely oriented complexes (as observed, for example, in Notch-Delta signaling) (Fortini 2009; Guruharsha et al. 2012) or between proximal and distal core PCP complexes (Tree et al. 2002b). A potential molecular underpinning of such a mechanism is suggested by the observed Ft-dependent proteolytic processing of Ds (Ambegaonkar et al. 2012). As mentioned above, Ds is endoproteolytically cleaved at either of two sites, each producing a distinct pair of polypeptides (Fig. 3). In the absence of $\mathrm{Ft}$, the preference for cleavage site changes such that, in wild-type tissue, there is more product from the more C-terminal cleavage, and in $f t$ mutant discs, cleavage occurs preferentially at the more $\mathrm{N}$-terminal site. The observed effect of Ft on Ds processing 
could be part of an amplification mechanism if one postulates that the alternative processing produces two differently functioning Ds isoforms. To understand the significance of the Ft-dependent cleavage choice, it will be important to determine whether cleavage results from cell-autonomous or nonautonomous interactions in addition to discerning potentially different behaviors of the alternatively cleaved isoforms.

\section{Possible mechanisms for molecular linkage between the Ft/Ds/Fj system and core PCP module}

A definitive mechanism has not yet been demonstrated that might transmit a directional signal from the $\mathrm{Ft} / \mathrm{Ds} / \mathrm{Fj}$ module to the core module, but several have been proposed, and more than one might contribute input to the core module. The $\mathrm{Ft} / \mathrm{Ds} / \mathrm{Fj}$ module potentially produces both transcriptional and nontranscriptional signals, but for the purposes of providing directional signals, asymmetric Ft-Ds subcellular localization would most plausibly provide directional cues by a direct nontranscriptional mechanism. The identification of Ft and Ds polarization across cells suggests possible mechanisms by which the $\mathrm{Ft} / \mathrm{Ds} / \mathrm{Fj}$ module could orient the core PCP module.

An attractive hypothesis for a molecular link between these two modules derives from the finding that the $\mathrm{Ft} /$ $\mathrm{Ds} / \mathrm{Fj}$ system spatially patterns the microtubule (MT) cytoskeleton. In the wing, noncentrosomal MTs spanning the apical aspect of the cell are aligned along the P-D axis, with a modest excess of plus ends on the distal side of the cell (Eaton et al. 1996; Shimada et al. 2006). These MTs contribute to the transport of $\mathrm{Fz}$ (and perhaps Dsh and Fmi) during the course of core PCP protein localization. At least a modicum of evidence indicates that MT polarization depends on $\mathrm{Ft} / \mathrm{Ds} / \mathrm{Fj}$ : Mutation of Ds has been found to alter MT orientation in a specific region of the wing, and graded misexpression of Ds reverses the direction of MT growth in a manner consistent with the hypothesis that MTs orient their plus ends in the direction of high-toward-low Ds expression (Harumoto et al. 2010). These data point toward a model in which polarization of $\mathrm{Ft}$ and Ds patterns the MT cytoskeleton, which in turn contributes to alignment of core module polarization. The polarized transport of Fz (or Dsh or Fmi) would only need to be sufficient to break the symmetry of the core module in a specified direction; the intrinsic amplifying function of the core module would then produce a robust polarization of core module proteins without relying on MT-based transport for bulk movement. The robust asymmetric accumulation of core proteins would then localize downstream targets that trigger actin organization and hair growth in a polarized manner.

A contrasting mechanism involving a different function for Ft and Ds has been proposed to contribute to the alignment of the core PCP module with the tissue axes in the wing. In the third instar wing disc, core PCP proteins organize in a radial pattern in the wing pouch, and, during pupal wing development, this radial pattern reorganizes into a parallel pattern aligned with the $\mathrm{P}-\mathrm{D}$ axis (Classen et al. 2005). The initial radial alignment of core PCP proteins in the third instar was proposed to depend on spontaneous organization (Aigouy et al. 2010) and subsequently was suggested to derive cues from known axial patterning systems that operate in the wing (Sagner et al. 2012). How these systems might orient PCP was not specified. A unique role for Ds and Ft was invoked to explain the reorganization from radial to parallel pattern during pupal development. Ds-dependent contraction of the hinge region of the wing during pupal development was found to induce tissue remodeling in large regions of the wing (Aigouy et al. 2010). This contraction was proposed to impose anisotropic tension on the wing blade, thereby inducing cell flow through junctional rearrangement-mediated neighbor exchange, cell elongation, and oriented cell divisions, and exert shear that would reorient PCP domains. Although it is not known what causes contraction of the hinge region, it is partially dependent on Ds, and one might imagine a mechanism similar to that which remodels the notum (Bosveld et al. 2012). In $d s$ mutant animals or in wing blades severed from the hinge, the normal pattern of cell flow, cell elongation, and oriented cell divisions is disrupted, and core module complexes are not correctly redistributed from the radial pattern to the mature P-D-aligned parallel pattern, suggesting a causal relationship.

While this model is appealing, several observations suggest that other contributions are required. The effect of $d s$ and $f t$ clones on polarity within the wing blade indicates local functions of these proteins in addition to their action in the hinge (Adler et al. 1998; Strutt and Strutt 2002; Ma et al. 2003, 2008). Furthermore, $f t$ and $d s$ mutant animals show perturbed polarity of core module proteins in third instar wing discs (Sagner et al. 2012), and timing experiments show requirements for Ds in the third instar (Matakatsu and Blair 2004; Aigouy et al. 2010), both indicating roles in PCP prior to pupal wing rearrangements. Notably, a reorganization of the Ds expression pattern in the wing occurs concomitantly with and may indeed be caused by hinge contraction (Matakatsu and Blair 2004; Hogan et al. 2011), possibly explaining reorganization from the radial to parallel PCP pattern (Bayly and Axelrod 2011). It is also worthwhile to point out that while the hinge contraction model is applicable to the wing, morphogenetic rearrangements that could allow a similar mechanism to explain $\mathrm{Ft} / \mathrm{Ds} / \mathrm{Fj}$ action in the eye and abdomen are not apparent.

Direct cytoskeletal signals are appealing candidates for transmitting directional information from the $\mathrm{Ft} / \mathrm{Ds} / \mathrm{Fj}$ module, but transcriptional mechanisms remain a possibility. It has been noted that within $f t$ or $d s$ clones in the eye, polarity is reversed in several rows of ommatidia at the polar or equatorial border of the clone, respectively (Sharma and McNeill 2013). Polarity propagation by the core module might account for this reversal and propagation. However, it has been noted that clones mutant for the Ft-binding transcriptional regulator Atrophin show the same effect as $f t$ clones inside the polar border, raising the possibility that a signal from Fat through Atrophin induces production of a diffusible signal to mediate the reversal. Since Atrophin only functions near the equator 
of the eye, other factors could perhaps play similar roles in other regions. Additional work will be required to define the signal mediating polarity propagation within $f t$ and $d s$ eye clones.

An unanswered question is the potential role of Dachs in PCP. Dachs is an unconventional myosin with clear importance in the regulation of the Hippo pathway by Ft. At least two examples in which polarization of Dachs is clearly regulated by the $\mathrm{Ft} / \mathrm{Ds} / \mathrm{Fj}$ system have been reported (Mao et al. 2011b; Bosveld et al. 2012). Polarized distribution of Dachs was shown to produce anisotropic junctional tension that contributes to the orientation of cell divisions (Mao et al. 2011b) and cell rearrangements (Bosveld et al. 2012). Together with the subtle polarity defects in dachs mutant tissue (Held et al. 1986), this polarization might suggest that Dachs is part of the mechanism that allows Ft/Ds/Fj to orient PCP. However, several observations argue against a model in which Dachs polarization plays a central role in the alignment of the core PCP module. First, the polarity defects in dachs mutant tissue range from very mild to undetectable in various tissues (Held et al. 1986; Mao et al. 2006). Second, the characterized examples in which Dachs functions as a myosin to regulate $\mathrm{Ft} / \mathrm{Ds} / \mathrm{Fj}$-dependent morphogenesis do not involve the core PCP module, suggesting that Dachs mediates a readout independent of orienting core PCP function. Although not yet clear, we suggest that Dachs is likely to have only indirect effects in regulating the polarity of hairs, bristles, or ommatidia either with or without the core module. Nonetheless, Dachs is an important part of the $\mathrm{Ft} / \mathrm{Ds} / \mathrm{Fj}$-dependent but (apparently) core module-independent morphogenetic processes regulating junctional tension and cell division orientation described above that should indeed be considered manifestations of PCP.

\section{Complexity of Fat activity in PCP}

Current models of Ft/Ds/Fj module polarization in PCP and in Hippo signaling depend on the observation that $\mathrm{Ft}$ and Ds heterodimerize through their cadherin domains and that orientation of these heterodimers results from expression gradients of $\mathrm{Ds}$ and $\mathrm{Fj}$. However, despite the essential role of cadherin domains in any simple model of this intercellular interaction, Fat protein derivatives lacking the cadherin domains (Ft $\Delta$ ECD) provide substantial polarity-rescuing activity in $\mathrm{ft}$-null mutant wing and abdominal tissue (Matakatsu and Blair 2006, 2012; Zhao et al. 2013). Clearly, the observation of activity in these derivatives implies a mechanism more complex than that outlined above. While it is probably premature to abandon the notion that $\mathrm{Ft}$ and Ds heterodimerization is an important part of a general mechanism of $\mathrm{Ft} / \mathrm{Ds} / \mathrm{Fj}$ function upon which some tissues (eye) rely more heavily than others, additional features of the mechanism undoubtedly remain to be discovered. Future analyses should consider the possibility of accessory proteins that participate in heterodimerization as well as the possibility that additional directional signals act by recruiting Ft, perhaps coopting its ability to organize apical MTs.
In addition to Ft and Ds heterodimerization, $\mathrm{Ft}$ and Ds may have an intrinsic, intracellular mechanism that might contribute to polarization, as discussed above. Such a polarizing mechanism could involve the Ft-dependent cell-autonomous endoproteolytic processing of Ds described earlier (Ambegaonkar et al. 2012). This interaction would not depend on the extracellular cadherin domains of Ft and Ds. One would expect that this type of polarization mechanism could read the Ds gradient but should be insensitive to Fj. Experimental support for this idea could come from the observation of polarized distribution of Ft and Ds lacking extracellular domains.

Another puzzling result is indicative of unexpected intracellular Ft-Ds interactions. Overexpression of a truncated Ds construct lacking the extracellular domain Ds $\triangle E C D$ has weak nonautonomous effects in the eye, suggesting a dominant-negative activity (Sharma and McNeill 2013). When overexpressed in a ds mutant clone, Ds $\triangle E C D$ produces substantial polarity reversal in the first row of ommatidia outside the equatorial border of the clone. Surprisingly, the nonautonomy depends on $\mathrm{Ft}$ within the clone, as the nonautonomy vanishes when the clones are mutant for both $f t$ and $d s$. Thus, the intracellular domain of Ds produces a Ft-dependent signal that is unexplained by the current, simple model of Ft-Ds interaction.

The observation that Ft $\Delta \mathrm{ECD}$ provides PCP-rescuing activity in $f t, d s$ double mutants in both the wing and abdomen (Matakatsu and Blair 2012) indicates that a mechanism other than a hypothetical intracellular Dsdependent polarization must come into play. One possibility is that the Ft intracellular domain contributes to polarization by regulating the MT cytoskeleton as discussed before but can be oriented by interaction with other global cues independent of $\mathrm{Ds}$ and $\mathrm{Fj}$. In other words, Ft could sit at the point of convergence of multiple global directional signals.

Three recent studies were able to take advantage of the rescuing activity of the Ft intracellular domain to map specific intracellular sequences with PCP activity in the fly wing and abdomen (Matakatsu and Blair 2012; Pan et al. 2013; Zhao et al. 2013). In all three structurefunction studies, a domain with PCP-rescuing activity was identified. In two studies, the mapped regions in the cytoplasmic domain overlap (Matakatsu and Blair 2012; Zhao et al. 2013), but the third study identified a nonoverlapping domain (Fig. 3; Pan et al. 2013). The two distinct PCP domains may interact with a common effector but might also reflect interactions with distinct effector pathways. In addition to identifying PCP domains, all three studies also mapped a domain responsible for suppressing overgrowth defects in $f t$ mutant tissues. Each of the three studies concluded that Ft PCP function is transduced by sequences distinct from those mediating Hippo activity. This is especially important for the correct interpretation of improved polarity when Ft Hippo activity is rescued, for example, by overexpressing Warts in ft-null tissues (Mao et al. 2006; Feng and Irvine 2007; Brittle et al. 2012). The strong polarity defects in $f t$ and $d s$ mutant tissue are therefore caused in part by the Hippo-dependent 
proliferative response, and suppressing this overgrowth by rescuing Hippo activity somewhat improves PCP. In this background, separating PCP and Hippo activities not only facilitated the demonstration that a truncated form of Ft with no Hippo activity recues PCP in the $f t$ mutant abdomen but also confirmed that regulation of the Hippo pathway by $\mathrm{Ft}$ is not necessary for producing PCP activity (Matakatsu and Blair 2012).

\section{Conservation of Fat/PCP in vertebrates}

In vertebrates, many feature of the PCP signaling pathway identified in insects are strongly conserved, regulating epithelial polarization as well as cell intercalations (convergent extension) during gastrulation and neurulation (for review, see Roszko et al. 2009). In addition to a strongly conserved core module (for review, see Goodrich and Strutt 2011), the mouse and human genomes encode four Ft homologs, two Ds homologs, and one Four-jointed homolog. Mice carrying a null mutation in the Fat4 (Saburi et al. 2008, 2012) or Ds1 (Mao et al. 2011a) gene show PCP-related developmental defects, including cystic kidneys as well as broader neural tubes and cochleae due to defects in convergent extension (Saburi et al. 2008, 2012; Mao et al. 2011a). Fat4 genetically interacts with Vangl2, a vertebrate homolog of Drosophila Vang (Saburi et al. 2008, 2012), suggesting that a Ft module likely interacts with a core module to regulate vertebrate PCP. Of the four Ft homologs, the intracellular domain of Fat4 shows the highest similarity to Drosophila Ft. Remarkably, the intracellular domain of mouse Fat4, in a chimera with the remainder of Drosophila Ft, can rescue PCP defects in the Drosophila wing and abdomen, suggesting that the mechanism of Ft function in flies and vertebrates is likely conserved (Pan et al. 2013).

\section{Concluding remarks}

Many components of the PCP signaling pathway have been identified and characterized in model organisms, and important inroads have been made in elucidating the molecular mechanism underlying PCP, although much remains to be learned. Further identification and characterization of upstream directional cues that link cellular polarity with tissue axes, including the $\mathrm{Ft} / \mathrm{Ds} / \mathrm{Fj}$ module, will be essential to understand the larger picture of PCP regulation. As related studies in vertebrates continue, it will be interesting to discover the range of variations and adaptations of the mechanism that participate in the more diverse morphogenetic events linked to vertebrate PCP signaling.

\section{Acknowledgments}

We thank members of the Axelrod laboratory for helpful comments on the manuscript. Work in the Axelrod laboratory is supported by grants from the NIH.

\section{References}

Adler PN, Charlton J, Liu J. 1998. Mutations in the cadherin superfamily member gene dachsous cause a tissue polarity phenotype by altering frizzled signaling. Development 125: 959-968.

Aigouy B, Farhadifar R, Staple DB, Sagner A, Roper JC, Julicher F, Eaton S. 2010. Cell flow reorients the axis of planar polarity in the wing epithelium of Drosophila. Cell 142: 773-786.

Ambegaonkar AA, Pan G, Mani M, Feng Y, Irvine KD. 2012. Propagation of Dachsous-Fat planar cell polarity. Curr Biol 22: $1302-1308$.

Amonlirdviman K, Khare NA, Tree DR, Chen WS, Axelrod JD, Tomlin CJ. 2005. Mathematical modeling of planar cell polarity to understand domineering nonautonomy. Science 307: 423-426.

Avery L, Wasserman S. 1992. Ordering gene function: The interpretation of epistasis in regulatory hierarchies. Trends Genet 8: 312-316.

Axelrod JD. 2009. Progress and challenges in understanding planar cell polarity signaling. Semin Cell Dev Biol 20: 964-971.

Bastock R, Strutt H, Strutt D. 2003. Strabismus is asymmetrically localised and binds to Prickle and Dishevelled during Drosophila planar polarity patterning. Development 130: 3007-3014.

Bayly R, Axelrod JD. 2011. Pointing in the right direction: New developments in the field of planar cell polarity. Nat Rev Genet 12: 385-391.

Bennett FC, Harvey KF. 2006. Fat cadherin modulates organ size in Drosophila via the Salvador/Warts/Hippo signaling pathway. Curr Biol 16: 2101-2110.

Bertet C, Lecuit T. 2009. Planar polarity and short-range polarization in Drosophila embryos. Semin Cell Dev Biol 20: 1006-1013.

Bosveld F, Bonnet I, Guirao B, Tlili S, Wang Z, Petitalot A, Marchand R, Bardet PL, Marcq P, Graner F, et al. 2012. Mechanical control of morphogenesis by Fat/Dachsous/ Four-jointed planar cell polarity pathway. Science 336: 724-727.

Brittle AL, Repiso A, Casal J, Lawrence PA, Strutt D. 2010. Fourjointed modulates growth and planar polarity by reducing the affinity of dachsous for fat. Curr Biol 20: 803-810.

Brittle A, Thomas C, Strutt D. 2012. Planar polarity specification through asymmetric subcellular localization of Fat and Dachsous. Curr Biol 22: 907-914.

Brodsky MH, Steller H. 1996. Positional information along the dorsal-ventral axis of the Drosophila eye: Graded expression of the four-jointed gene. Dev Biol 173: 428-446.

Caddy J, Wilanowski T, Darido C, Dworkin S, Ting SB, Zhao Q, Rank G, Auden A, Srivastava S, Papenfuss TA, et al. 2010. Epidermal wound repair is regulated by the planar cell polarity signaling pathway. Dev Cell 19: 138-147.

Casal J, Struhl G, Lawrence PA. 2002. Developmental compartments and planar polarity in Drosophila. Curr Biol 12: 11891198.

Casal J, Lawrence PA, Struhl G. 2006. Two separate molecular systems, Dachsous/Fat and Starry night/Frizzled, act independently to confer planar cell polarity. Development 133: 4561-4572.

Chae J, Kim MJ, Goo JH, Collier S, Gubb D, Charlton J, Adler PN, Park WJ. 1999. The Drosophila tissue polarity gene starry night encodes a member of the protocadherin family. Development 126: 5421-5429.

Chen WS, Antic D, Matis M, Logan CY, Povelones M, Anderson GA, Nusse R, Axelrod JD. 2008. Asymmetric homotypic interactions of the atypical cadherin flamingo mediate intercellular polarity signaling. Cell 133: 1093-1105.

Chin ML, Mlodzik M. 2013. The Drosophila selectin Furrowed mediates intercellular planar cell polarity interactions via Frizzled stabilization. Dev Cell 26: 455-468. 
Cho E, Irvine KD. 2004. Action of fat, four-jointed, dachsous and dachs in distal-to-proximal wing signaling. Development 131: 4489-4500.

Cho E, Feng Y, Rauskolb C, Maitra S, Fehon R, Irvine KD. 2006. Delineation of a Fat tumor suppressor pathway. Nat Genet 38: $1142-1150$.

Clark HF, Brentrup D, Schneitz K, Bieber A, Goodman C, Noll M. 1995. dachsous encodes a member of the cadherin superfamily that controls imaginal disc morphogenesis in Drosophila. Genes Dev 9: 1530-1542.

Classen AK, Anderson KI, Marois E, Eaton S. 2005. Hexagonal packing of Drosophila wing epithelial cells by the planar cell polarity pathway. Dev Cell 9: 805-817.

Cooper MT, Bray SJ. 1999. Frizzled regulation of Notch signalling polarizes cell fate in the Drosophila eye. Nature 397: 526-530.

Copp AJ, Greene ND. 2010. Genetics and development of neural tube defects. I Pathol 220: 217-230.

Couso JP, Bishop SA, Martinez Arias A. 1994. The wingless signalling pathway and the patterning of the wing margin in Drosophila. Development 120: 621-636.

Coyle RC, Latimer A, Jessen JR. 2008. Membrane-type 1 matrix metalloproteinase regulates cell migration during zebrafish gastrulation: Evidence for an interaction with non-canonical Wnt signaling. Exp Cell Res 314: 2150-2162.

Curtin JA, Quint E, Tsipouri V, Arkell RM, Cattanach B, Copp AJ, Henderson DJ, Spurr N, Stanier P, Fisher EM, et al. 2003. Mutation of Celsr1 disrupts planar polarity of inner ear hair cells and causes severe neural tube defects in the mouse. Curr Biol 13: 1129-1133.

Das G, Jenny A, Klein TJ, Eaton S, Mlodzik M. 2004. Diego interacts with Prickle and Strabismus/Van Gogh to localize planar cell polarity complexes. Development 131: 4467-4476.

Davies A, Formstone C, Mason I, Lewis J. 2005. Planar polarity of hair cells in the chick inner ear is correlated with polarized distribution of c-flamingo-1 protein. Dev Dyn 233: 998-1005.

Deans MR, Antic D, Suyama K, Scott MP, Axelrod JD, Goodrich LV. 2007. Asymmetric distribution of prickle-like 2 reveals an early underlying polarization of vestibular sensory epithelia in the inner ear. I Neurosci 27: 3139-3147.

Dong J, Feldmann G, Huang J, Wu S, Zhang N, Comerford SA, Gayyed MF, Anders RA, Maitra A, Pan D. 2007. Elucidation of a universal size-control mechanism in Drosophila and mammals. Cell 130: 1120-1133.

Donoughe S, DiNardo S. 2011. dachsous and frizzled contribute separately to planar polarity in the Drosophila ventral epidermis. Development 138: 2751-2759.

Eaton S, Wepf R, Simons K. 1996. Roles for Rac1 and Cdc42 in planar polarization and hair outgrowth in the wing of Drosophila. I Cell Biol 135: 1277-1289.

Fanto M, Mlodzik M. 1999. Asymmetric Notch activation specifies photoreceptors R3 and R4 and planar polarity in the Drosophila eye. Nature 397: 523-526.

Fanto M, Clayton L, Meredith J, Hardiman K, Charroux B, Kerridge S, McNeill H. 2003. The tumor-suppressor and cell adhesion molecule Fat controls planar polarity via physical interactions with Atrophin, a transcriptional co-repressor. Development 130: 763-774.

Feiguin F, Hannus M, Mlodzik M, Eaton S. 2001. The ankyrin repeat protein Diego mediates Frizzled-dependent planar polarization. Dev Cell 1: 93-101.

Feng Y, Irvine KD. 2007. Fat and expanded act in parallel to regulate growth through warts. Proc Natl Acad Sci 104: 20362-20367.

Feng Y, Irvine KD. 2009. Processing and phosphorylation of the Fat receptor. Proc Natl Acad Sci 106: 11989-11994.
Fortini ME. 2009. Notch signaling: The core pathway and its posttranslational regulation. Dev Cell 16: 633-647.

Gao B, Yang Y. 2013. Planar cell polarity in vertebrate limb morphogenesis. Curr Opin Genet Dev 23: 438-444.

Garriock RJ, D'Agostino SL, Pilcher KC, Krieg PA. 2005. Wnt11$\mathrm{R}$, a protein closely related to mammalian $\mathrm{Wnt} 11$, is required for heart morphogenesis in Xenopus. Dev Biol 279: 179-192.

Goodrich LV, Strutt D. 2011. Principles of planar polarity in animal development. Development 138: 1877-1892.

Gubb D, Green C, Huen D, Coulson D, Johnson G, Tree D, Collier S, Roote J. 1999. The balance between isoforms of the prickle LIM domain protein is critical for planar polarity in Drosophila imaginal discs. Genes Dev 13: 2315-2327.

Guruharsha KG, Kankel MW, Artavanis-Tsakonas S. 2012. The Notch signalling system: Recent insights into the complexity of a conserved pathway. Nat Rev Genet 13: 654-666.

Gutzeit HO. 1990. The microfilament pattern in the somatic follicle cells of mid-vitellogenic ovarian follicles of Drosophila. Eur J Cell Biol 53: 349-356.

Harumoto T, Ito M, Shimada Y, Kobayashi TJ, Ueda HR, Lu B, Uemura T. 2010. Atypical cadherins Dachsous and Fat control dynamics of noncentrosomal microtubules in planar cell polarity. Dev Cell 19: 389-401.

Held LI Jr, Duarte CM, Derakhshanian K. 1986. Extra joints and misoriented bristles on Drosophila legs. Prog Clin Biol Res 217A: 293-296.

Henderson DJ, Phillips HM, Chaudhry B. 2006. Vang-like 2 and noncanonical Wnt signaling in outflow tract development. Trends Cardiovasc Med 16: 38-45.

Hogan I, Valentine M, Cox C, Doyle K, Collier S. 2011. Two frizzled planar cell polarity signals in the Drosophila wing are differentially organized by the Fat/Dachsous pathway. PLoS Genet 7: e1001305.

Huang J, Wu S, Barrera J, Matthews K, Pan D. 2005. The Hippo signaling pathway coordinately regulates cell proliferation and apoptosis by inactivating Yorkie, the Drosophila homolog of YAP. Cell 122: 421-434.

Ishikawa HO, Takeuchi H, Haltiwanger RS, Irvine KD. 2008. Four-jointed is a Golgi kinase that phosphorylates a subset of cadherin domains. Science 321: 401-404.

Jenny A, Darken RS, Wilson PA, Mlodzik M. 2003. Prickle and Strabismus form a functional complex to generate a correct axis during planar cell polarity signaling. EMBO J 22: 44094420.

Jenny A, Reynolds-Kenneally J, Das G, Burnett M, Mlodzik M. 2005. Diego and Prickle regulate Frizzled planar cell polarity signalling by competing for Dishevelled binding. Nat Cell Biol 7: 691-697.

Jones C, Roper VC, Foucher I, Qian D, Banizs B, Petit C, Yoder BK, Chen P. 2008. Ciliary proteins link basal body polarization to planar cell polarity regulation. Nat Genet 40: 69-77.

Katoh M. 2005. WNT/PCP signaling pathway and human cancer. Oncol Rep 14: 1583-1588.

Klingensmith J, Nusse R, Perrimon N. 1994. The Drosophila segment polarity gene dishevelled encodes a novel protein required for response to the wingless signal. Genes Dev 8: $118-130$

Kuriyama S, Mayor R. 2008. Molecular analysis of neural crest migration. Philos Trans R Soc Lond B Biol Sci 363: 13491362.

Lawrence PA, Casal J, Struhl G. 2002. Towards a model of the organisation of planar polarity and pattern in the Drosophila abdomen. Development 129: 2749-2760.

Lawrence PA, Casal J, Struhl G. 2004. Cell interactions and planar polarity in the abdominal epidermis of Drosophila. Development 131: 4651-4664. 
Lawrence PA, Struhl G, Casal J. 2007. Planar cell polarity: One or two pathways? Nat Rev Genet 8: 555-563.

Lee H, Adler PN. 2004. The grainy head transcription factor is essential for the function of the frizzled pathway in the Drosophila wing. Mech Dev 121: 37-49.

Lee JH, Park SR, Chay KO, Seo YW, Kook H, Ahn KY, Kim YJ, Kim KK. 2004. KAIl COOH-terminal interacting tetraspanin (KITENIN), a member of the tetraspanin family, interacts with KAIl, a tumor metastasis suppressor, and enhances metastasis of cancer. Cancer Res 64: 4235-4243.

Lim J, Norga KK, Chen Z, Choi KW. 2005. Control of planar cell polarity by interaction of DWnt4 and four-jointed. Genesis 42: $150-161$.

Lu X, Borchers AG, Jolicoeur C, Rayburn H, Baker JC, TessierLavigne M. 2004. PTK7/CCK-4 is a novel regulator of planar cell polarity in vertebrates. Nature 430: 93-98.

Ma D, Yang CH, McNeill H, Simon MA, Axelrod JD. 2003. Fidelity in planar cell polarity signalling. Nature 421: 543-547.

Ma D, Amonlirdviman K, Raffard RL, Abate A, Tomlin CJ, Axelrod JD. 2008. Cell packing influences planar cell polarity signaling. Proc Natl Acad Sci 105: 18800-18805.

Mahoney PA, Weber U, Onofrechuk P, Biessmann H, Bryant PJ, Goodman CS. 1991. The fat tumor suppressor gene in Drosophila encodes a novel member of the cadherin gene superfamily. Cell 67: 853-868.

Mao Y, Rauskolb C, Cho E, Hu WL, Hayter H, Minihan G, Katz FN, Irvine KD. 2006. Dachs: An unconventional myosin that functions downstream of Fat to regulate growth, affinity and gene expression in Drosophila. Development 133: 25392551.

Mao Y, Kucuk B, Irvine KD. 2009. Drosophila lowfat, a novel modulator of Fat signaling. Development 136: 3223-3233.

Mao Y, Mulvaney J, Zakaria S, Yu T, Morgan KM, Allen S, Basson MA, Francis-West P, Irvine KD. 2011a. Characterization of a Dchs1 mutant mouse reveals requirements for Dchs1-Fat4 signaling during mammalian development. Development 138: 947-957.

Mao Y, Tournier AL, Bates PA, Gale JE, Tapon N, Thompson BJ. 2011b. Planar polarization of the atypical myosin Dachs orients cell divisions in Drosophila. Genes Dev 25: 131-136.

Matakatsu H, Blair SS. 2004. Interactions between Fat and Dachsous and the regulation of planar cell polarity in the Drosophila wing. Development 131: 3785-3794.

Matakatsu H, Blair SS. 2006. Separating the adhesive and signaling functions of the Fat and Dachsous protocadherins. Development 133: 2315-2324.

Matakatsu H, Blair SS. 2012. Separating planar cell polarity and Hippo pathway activities of the protocadherins Fat and Dachsous. Development 139: 1498-1508.

Montcouquiol M, Rachel RA, Lanford PI, Copeland NG, Jenkins NA, Kelley MW. 2003. Identification of Vangl2 and Scrb1 as planar polarity genes in mammals. Nature 423: 173-177.

Montcouquiol M, Sans N, Huss D, Kach J, Dickman JD, Forge A, Rachel RA, Copeland NG, Jenkins NA, Bogani D, et al. 2006. Asymmetric localization of Vangl2 and Fz3 indicate novel mechanisms for planar cell polarity in mammals. J Neurosci 26: 5265-5275.

Pan G, Feng Y, Ambegaonkar AA, Sun G, Huff M, Rauskolb C, Irvine KD. 2013. Signal transduction by the Fat cytoplasmic domain. Development 140: 831-842.

Phillips HM, Murdoch JN, Chaudhry B, Copp AJ, Henderson DJ. 2005. Vangl2 acts via RhoA signaling to regulate polarized cell movements during development of the proximal outflow tract. Circ Res 96: 292-299.

Phillips HM, Rhee HJ, Murdoch JN, Hildreth V, Peat JD, Anderson RH, Copp AJ, Chaudhry B, Henderson DJ. 2007.
Disruption of planar cell polarity signaling results in congenital heart defects and cardiomyopathy attributable to early cardiomyocyte disorganization. Circ Res 101: 137-145.

Price $\mathrm{MH}$, Roberts DM, McCartney BM, Jezuit E, Peifer M. 2006. Cytoskeletal dynamics and cell signaling during planar polarity establishment in the Drosophila embryonic denticle. J Cell Sci 119: 403-415.

Qian D, Jones C, Rzadzinska A, Mark S, Zhang X, Steel KP, Dai X, Chen P. 2007. Wnt5a functions in planar cell polarity regulation in mice. Dev Biol 306: 121-133.

Reddy BV, Irvine KD. 2008. The Fat and Warts signaling pathways: New insights into their regulation, mechanism and conservation. Development 135: 2827-2838.

Repiso A, Saavedra P, Casal J, Lawrence PA. 2010. Planar cell polarity: The orientation of larval denticles in Drosophila appears to depend on gradients of Dachsous and Fat. Development 137: 3411-3415.

Rogulja D, Rauskolb C, Irvine KD. 2008. Morphogen control of wing growth through the Fat signaling pathway. Dev Cell 15: 309-321.

Roszko I, Sawada A, Solnica-Krezel L. 2009. Regulation of convergence and extension movements during vertebrate gastrulation by the Wnt/PCP pathway. Semin Cell Dev Biol 20: 986-997.

Saburi S, Hester I, Fischer E, Pontoglio M, Eremina V, Gessler M, Quaggin SE, Harrison R, Mount R, McNeill H. 2008. Loss of Fat4 disrupts PCP signaling and oriented cell division and leads to cystic kidney disease. Nat Genet 40: 1010-1015.

Saburi S, Hester I, Goodrich L, McNeill H. 2012. Functional interactions between Fat family cadherins in tissue morphogenesis and planar polarity. Development 139: 1806-1820.

Sagner A, Merkel M, Aigouy B, Gaebel J, Brankatschk M, Julicher F, Eaton S. 2012. Establishment of global patterns of planar polarity during growth of the Drosophila wing epithelium. Curr Biol 22: 1296-1301.

Santos N, Reiter JF. 2010. Tilting at nodal windmills: Planar cell polarity positions cilia to tell left from right. Dev Cell 19: 5-6.

Sharma P, McNeill H. 2013. Regulation of long-range planar cell polarity by Fat-Dachsous signaling. Development 140: 38693881.

Shimada Y, Yonemura S, Ohkura H, Strutt D, Uemura T. 2006. Polarized transport of Frizzled along the planar microtubule arrays in Drosophila wing epithelium. Dev Cell 10: 209-222.

Silva E, Tsatskis Y, Gardano L, Tapon N, McNeill H. 2006. The tumor-suppressor gene fat controls tissue growth upstream of expanded in the hippo signaling pathway. Curr Biol 16: 2081-2089.

Simon MA. 2004. Planar cell polarity in the Drosophila eye is directed by graded Four-jointed and Dachsous expression. Development 131: 6175-6184.

Simon MA, Xu A, Ishikawa HO, Irvine KD. 2010. Modulation of fat:dachsous binding by the cadherin domain kinase fourjointed. Curr Biol 20: 811-817.

Simons M, Mlodzik M. 2008. Planar cell polarity signaling: From fly development to human disease. Annu Rev Genet 42: 517-540.

Simons M, Walz G. 2006. Polycystic kidney disease: Cell division without a c(1)ue? Kidney Int 70: 854-864.

Sopko R, Silva E, Clayton L, Gardano L, Barrios-Rodiles M, Wrana J, Varelas X, Arbouzova NI, Shaw S, Saburi S, et al. 2009. Phosphorylation of the tumor suppressor fat is regulated by its ligand Dachsous and the kinase discs overgrown. Curr Biol 19: 1112-1117.

Staley BK, Irvine KD. 2012. Hippo signaling in Drosophila: Recent advances and insights. Dev Dyn 241: 3-15. 
Struhl G, Barbash DA, Lawrence PA. 1997. Hedgehog organises the pattern and polarity of epidermal cells in the Drosophila abdomen. Development 124: 2143-2154.

Strutt DI. 2001. Asymmetric localization of frizzled and the establishment of cell polarity in the Drosophila wing. Mol Cell 7: 367-375.

Strutt H, Strutt D. 2002. Nonautonomous planar polarity patterning in Drosophila: dishevelled-independent functions of frizzled. Dev Cell 3: 851-863.

Strutt D, Strutt H. 2007. Differential activities of the core planar polarity proteins during Drosophila wing patterning. Dev Biol 302: 181-194.

Strutt H, Strutt D. 2009. Asymmetric localisation of planar polarity proteins: Mechanisms and consequences. Semin Cell Dev Biol 20: 957-963.

Strutt D, Johnson R, Cooper K, Bray S. 2002. Asymmetric localization of frizzled and the determination of notchdependent cell fate in the Drosophila eye. Curr Biol 12: 813-824.

Strutt H, Mundy J, Hofstra K, Strutt D. 2004. Cleavage and secretion is not required for Four-jointed function in Drosophila patterning. Development 131: 881-890.

Swaney KF, Huang CH, Devreotes PN. 2010. Eukaryotic chemotaxis: A network of signaling pathways controls motility, directional sensing, and polarity. Annu Rev Biophys 39: 265289.

Taylor J, Abramova N, Charlton J, Adler PN. 1998. Van Gogh: A new Drosophila tissue polarity gene. Genetics 150: 199210.

Theisen H, Purcell J, Bennett M, Kansagara D, Syed A, Marsh JL. 1994. dishevelled is required during wingless signaling to establish both cell polarity and cell identity. Development 120: $347-360$.

Tree DR, Ma D, Axelrod JD. 2002a. A three-tiered mechanism for regulation of planar cell polarity. Semin Cell Dev Biol 13: 217-224.

Tree DR, Shulman JM, Rousset R, Scott MP, Gubb D, Axelrod JD. 2002b. Prickle mediates feedback amplification to generate asymmetric planar cell polarity signaling. Cell 109: 371-381.

Usui T, Shima Y, Shimada Y, Hirano S, Burgess RW, Schwarz TL, Takeichi M, Uemura T. 1999. Flamingo, a seven-pass transmembrane cadherin, regulates planar cell polarity under the control of Frizzled. Cell 98: 585-595.

Vichas A, Zallen JA. 2011. Translating cell polarity into tissue elongation. Semin Cell Dev Biol 22: 858-864.

Viktorinova I, Konig T, Schlichting K, Dahmann C. 2009. The cadherin Fat2 is required for planar cell polarity in the Drosophila ovary. Development 136: 4123-4132.

Villano JL, Katz FN. 1995. four-jointed is required for intermediate growth in the proximal-distal axis in Drosophila. Development 121: 2767-2777.

Vinson CR, Adler PN. 1987. Directional non-cell autonomy and the transmission of polarity information by the frizzled gene of Drosophila. Nature 329: 549-551.

Vinson CR, Conover S, Adler PN. 1989. A Drosophila tissue polarity locus encodes a protein containing seven potential transmembrane domains. Nature 338: 263-264.

Vladar EK, Antic D, Axelrod JD. 2009. Planar cell polarity signaling: The developing cell's compass. Cold Spring Harb Perspect Biol 1: a002964.

Wallingford JB. 2006. Planar cell polarity, ciliogenesis and neural tube defects. Hum Mol Genet 15: R227-R234.

Wallingford JB. 2012. Planar cell polarity and the developmental control of cell behavior in vertebrate embryos. Annu Rev Cell Dev Biol 28: 627-653.
Wang Y, Nathans J. 2007. Tissue/planar cell polarity in vertebrates: New insights and new questions. Development 134: 647-658.

Wang J, Mark S, Zhang X, Qian D, Yoo SJ, Radde-Gallwitz K, Zhang Y, Lin X, Collazo A, Wynshaw-Boris A, et al. 2005. Regulation of polarized extension and planar cell polarity in the cochlea by the vertebrate PCP pathway. Nat Genet 37: 980-985.

Wang J, Hamblet NS, Mark S, Dickinson ME, Brinkman BC, Segil N, Fraser SE, Chen P, Wallingford JB, Wynshaw-Boris A. 2006a. Dishevelled genes mediate a conserved mammalian PCP pathway to regulate convergent extension during neurulation. Development 133: 1767-1778.

Wang Y, Guo N, Nathans J. 2006b. The role of Frizzled3 and Frizzled6 in neural tube closure and in the planar polarity of inner-ear sensory hair cells. I Neurosci 26: 2147-2156.

Weeraratna AT, Jiang Y, Hostetter G, Rosenblatt K, Duray P, Bittner M, Trent JM. 2002. Wnt5a signaling directly affects cell motility and invasion of metastatic melanoma. Cancer Cell 1: 279-288.

Willecke M, Hamaratoglu F, Kango-Singh M, Udan R, Chen CL, Tao C, Zhang X, Halder G. 2006. The fat cadherin acts through the hippo tumor-suppressor pathway to regulate tissue size. Curr Biol 16: 2090-2100.

Wolff T, Rubin GM. 1998. Strabismus, a novel gene that regulates tissue polarity and cell fate decisions in Drosophila. Development 125: 1149-1159.

Wong HC, Bourdelas A, Krauss A, Lee HJ, Shao Y, Wu D, Mlodzik M, Shi DL, Zheng J. 2003. Direct binding of the PDZ domain of Dishevelled to a conserved internal sequence in the C-terminal region of Frizzled. Mol Cell 12: 1251-1260.

Wu J, Mlodzik M. 2008. The frizzled extracellular domain is a ligand for Van Gogh/Stbm during nonautonomous planar cell polarity signaling. Dev Cell 15: 462-469.

Wu J, Roman AC, Carvajal-Gonzalez JM, Mlodzik M. 2013. Wg and Wnt4 provide long-range directional input to planar cell polarity orientation in Drosophila. Nat Cell Biol 15: 1045-1055.

Yang CH, Axelrod JD, Simon MA. 2002. Regulation of Frizzled by fat-like cadherins during planar polarity signaling in the Drosophila compound eye. Cell 108: 675-688.

Zallen JA. 2007. Planar polarity and tissue morphogenesis. Cell 129: 1051-1063.

Zecca M, Struhl G. 2010. A feed-forward circuit linking wingless, Fat-Dachsous signaling, and the warts-hippo pathway to Drosophila wing growth. PLoS Biol 8: e1000386.

Zeidler MP, Perrimon N, Strutt DI. 1999. The four-jointed gene is required in the Drosophila eye for ommatidial polarity specification. Curr Biol 9: 1363-1372.

Zeidler MP, Perrimon N, Strutt DI. 2000. Multiple roles for fourjointed in planar polarity and limb patterning. Dev Biol 228: 181-196.

Zhao X, Yang CH, Simon MA. 2013. The Drosophila cadherin fat regulates tissue size and planar cell polarity through different domains. PLOS ONE 8: e62998.

Zheng L, Zhang J, Carthew RW. 1995. frizzled regulates mirrorsymmetric pattern formation in the Drosophila eye. Development 121: 3045-3055. 


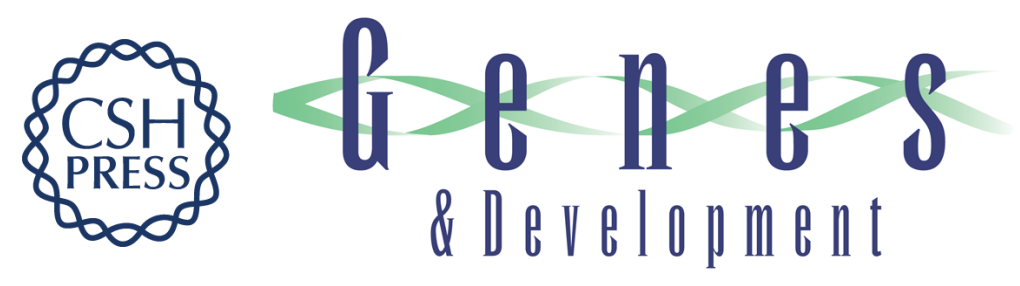

\title{
Regulation of PCP by the Fat signaling pathway
}

\author{
Maja Matis and Jeffrey D. Axelrod
}

Genes Dev. 2013, 27:

Access the most recent version at doi:10.1101/gad.228098.113

References This article cites 138 articles, 54 of which can be accessed free at: http://genesdev.cshlp.org/content/27/20/2207.full.html\#ref-list-1

Creative This article is distributed exclusively by Cold Spring Harbor Laboratory Press for the first Commons six months after the full-issue publication date (see License http://genesdev.cshlp.org/site/misc/terms.xhtml). After six months, it is available under a Creative Commons License (Attribution-NonCommercial 3.0 Unported), as described at http://creativecommons.org/licenses/by-nc/3.0/.

Email Alerting Receive free email alerts when new articles cite this article - sign up in the box at the top Service right corner of the article or click here.

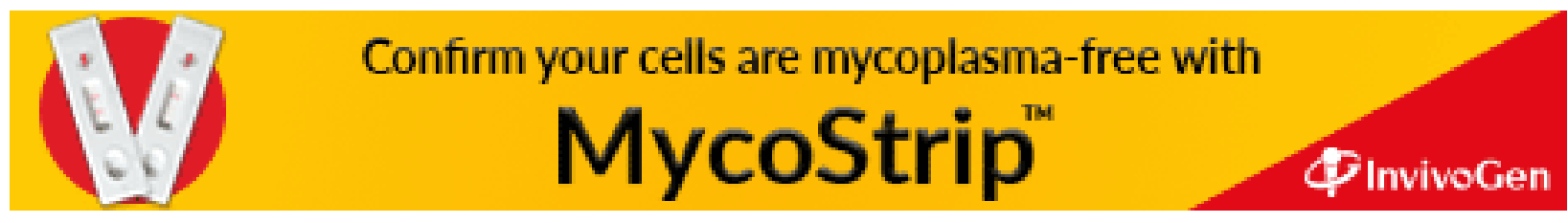

